\title{
Effects of Human Placental Amnion Derived Mesenchymal Stem Cells on Proliferation and Apoptosis Mechanisms in Chronic Kidney Disease in the Rat
}

\author{
Busra Cetinkaya ${ }^{1,4}$, Gozde Unek ${ }^{1}$, Dijle Kipmen-Korgun², Sadi Koksoy ${ }^{3}$, Emin Turkay Korgun ${ }^{1}$ \\ ${ }^{1}$ Departments of Histology and Embryology, ${ }^{2}$ Medical Biochemistry, \\ ${ }^{3}$ Medical Microbiology and Immunology, Medical Faculty, Akdeniz University, Antalya, Turkey, \\ ${ }^{4}$ Department of Histology and Embryology, Medical Faculty, Bulent Ecevit University, Zonguldak, Turkey
}

Background and Objectives: The feature of chronic kidney failure (CKF) is loss of kidney functions due to erosion of healthy tissue and fibrosis. Recent studies showed that Mesenchymal stem cells (MSCs) differentiated into tubular epithelial cells thus renal function and structures renewed.Furthermore, MSCs protect renal function in CKF. Therefore, we aimed to investigate whether human amnion-derived mesenchymal stem cells (hAMSCs) can repair fibrosis and determine the effects on proliferation and apoptosis mechanisms in chronic kidney failure.

Methods and Results: In this study, rat model of CKF was constituted by applying Aristolochic acid (AA). hAMSCs were isolated from term placenta amnion membrane and transplanted into tail vein of rats. At the end of 30 days and 60 days of recovery period, we examined expressions of PCNA, p57 and Parp-1 by western blotting. Immunoreactivity of PCNA, Ki67, IL-6 and Collagen type I were detected by immunohistochemistry. Besides, apoptosis was detected by TUNEL. Serum creatinine and urea were measured. Expressions of PCNA and Ki67 increased in hAMSC groups compared with AA group. Furthermore, expressions of PARP-1 apoptosis marker and p57 cell cycle inhibitory protein increased in AA group significantly according to control, hAMSC groups and sham groups. IL-6 proinflammatory cytokine increased in AA group significantly according to control, hAMSCs groups and sham groups. Expressions of Collagen type I protein reduced in hAMSCs groups compared to AA group. After hAMSC treatment, serum creatinine and urea levels significantly decreased compared to AA group. After injection of hAMSC to rats, Masson's Trichrome and Sirius Red staining showed fibrosis reduction in kidney.

Conclusions: According to our results hAMSCs can be ameliorate renal failure.

Keywords: Human amnion derived mesenchymal stem cells, Chronic kidney failure, Apoptosis, Proliferation, Rat

Received: August 15, 2018, Revised: August 21, 2018,

Accepted: November 20, 2018, Published online: December 31, 2018 Correspondence to Emin Turkay Korgun

Department of Histology and Embryology, Medical Faculty, Akdeniz University, Antalya 07070, Turkey

Tel: +90-242-2496885, Fax: +90-242-2274495

E-mail: korgun@akdeniz.edu.tr

(c) This is an open-access article distributed under the terms of the Creative Commons Attribution Non-Commercial License (http://creativecommons.org/ licenses/by-nc/4.0/), which permits unrestricted non-commercial use, distribution, and reproduction in any medium, provided the original work is properly cited.

Copyright (c) 2019 by the Korean Society for Stem Cell Research

\section{Introduction}

Chronic kidney injury can progress end-stage renal failure that causes an irreversible glomerular and tubular damage lead to loss of renal function (1). Apoptosis, oxidative damage and microvascular rarefaction are responsible for glomerular and tubulointerstitial fibrosis in chronic kidney failure (2).

Aristolochic acid (AA) is obtained from the Chinese herb Aristolochic fangchi (3). In recent studies showed that AA leads to renal damage has been identified (4). AA effects on proximal tubular cells and causes Chronic Kidney 
Diseases (CKD) and AA nephropathy (AAN) create progress fibrosis rapidly (5). Therefore, renal functions deteriorate and end stage renal failure occurs in a short while (6). Several studies asserted that specific AA-DNA adducts formation in renal epithelial cells after AA injection and these adducts effect proximal tubular epithelial cells (PTEC) regeneration negatively leading to apoptosis. Therefore, irreversible proximal tubular atrophy occurs (7-11). CKD is caused by the development of renal fibrosis. It is characterized by renal interstitial fibrosis, tubular atrophy, interstitial inflammatory cell infiltration, and interstitial matrix accumulation. In fibrotic kidneys, type 1 and type 3 together with basal membrane type 4 collagen are the most common types of collagen. Kidney fibrosis is characterized by collagen synthesis accumulation, cross-linking and decreased degradation $(12,13)$. AAN patients are observed high serum creatinine rate with anemia and proteinuria. AA induces loss of peritubular capillary that results of hypoxia and tubular cell death $(14,15)$. Transplantation of mesenchymal stem cells (MSCs) was performed to provide renal repairment of damaged kidney in most of studies. Therefore, stem cells were considered therapeutic tool for the treatment of kidney diseases (16-20).

Placenta is used as a source of MSCs alternatively and placenta is an important reserve for stem cells and progenitor cells. Chorionic villus, amniotic membrane, umbilical cord stroma and amniotic fluid are indicated as a source of MSCs in placenta $(21,22)$. Diaz-Prado and colleagues determined that isolation, localization, phenotypic characterization and differentiation potential of human amniotic mesenchymal stem cells (hAMSC) (23). AMSC show plastic adherence and fibroblast-like growth as MSCs obtained from bone marrow. They express specific cell surface markers such as CD90, CD44, CD73, CD105, CD166 and CD29 and lack expression CD45, CD34, CD14, HLA-DR $(23,24)$.

Several studies demonstrated the effect of MSCs that obtain from bone marrow on CKD (25-28). However, effects of placental-derived mesenchymal stem cell in CKD experiments are limited. In the present study, we aimed to investigate whether amnion membrane derived mesenchymal stem cells can repair fibrosis that occurs because of chronic kidney failure and they are effective in mechanisms of proliferation and apoptosis.

\section{Materials and Methods}

\section{Isolation of human amnion derived mesenchymal stem cells}

Human term placentas of normal pregnancies (range 38 42 weeks, $n=6$ ) were obtained after spontaneous delivery or caesarean section with informed consent. Approval of the Ethical Committee of the Medical University of Akdeniz was granted. Isolation of hAMSC was performed according to the protocol of Soncini et al 2007 using enzymatic treatment of the amnion with collagenase $\mathrm{A}$ and DNase (both from Roche, Penzberg, Germany) after manual separation from the chorion (29). hAMSC were cultured in DMEM (Lonza, Basel, Switzerland) low glucose supplemented with 15\% FBS (FBS Gold, both from Gibco, Invitrogen, Paisley, UK).

\section{Immunophenotyping of cells}

The cell surface marker phenotype of these hAMSCs was analyzed by flow cytometry and shown to be for $\mathrm{CD} 90+$, $\mathrm{CD} 105+, \mathrm{CD} 73+, \mathrm{CD} 44+$ and negative cocktail containing CD34, CD11b, CD19, CD45 and HLA-DR. hAMSCs were analyzed with a FACS Aria III Cell Sorter flow cytometry and the CellQuest software (BD Biosciences, New Jersey, USA).

\section{Chondrogenic, osteogenic and adipogenic differentiation}

For induction of osteogenic, chondrogenic, or adipogenic differentiation, hAMSCs were cultured in StemPro Osteogenic, StemPro Chondrogenic, or StemPro Adipogenic differentiation media(Life Tech, Carlsbad, USA), respectively, and with appropriate supplements. At week 3 of postosteogenic, postchondrogenic and postadipogenic inductions cells were washed with phosphate buffered saline (PBS) and fixed in 4\% paraformaldehyde for $10 \mathrm{~min}$. The cells were stained with Alizarin Red, Alcian Blue, and Oil Red O dyes (Sigma-Aldrich, St Louis, USA) for detection of calcium deposits, proteoglycans, and fat vacuoles as an indication of osteogenic, chondrogenic, and adipogenic differentiations, respectively.

\section{Animal experiment}

The study involving both human (File No: 294) and animals (File No: 2014.07.03) was conducted in accordance with the principles of the Helsinki Declaration and was approved by the ethical committee of Akdeniz University.

Aristolochic acid I (AA; Sigma-Aldrich, St Louis, USA) was used to mimic the structural and functional damage of CKD. AA was dissolved in Dimethyl sulfoxide (DMSO, 
Sigma-Aldrich, St Louis, USA). Animals were randomized in 6 groups. (i) Control group $(n=5)$, Sham groups that received intraperitoneal injection of DMSO as a vehicle for 6 weeks. (ii) After 6 weeks one of the Sham groups was waited for 30 days $(S+30 ; n=5)$ and (iii) the other Sham group was waited for 60 days $(S+60 ; n=6)$ and sacrificed (iv). Every three days, rats received intraperitoneal injections of $10 \mathrm{mg} / \mathrm{kg}$ body weight $\mathrm{AA}$ for six weeks to induce AA group $(n=6)$. After AA was taken, we waited six weeks thus we made a model of CKD. Then AA group was sacrificed. In hAMSCs groups, after rats were received AA for six weeks, $6 \times 10^{5}$ hAMSCs were injected from in the tail vein with $500 \mu 1$ DMEM medium. (v) One of hAMSCs group was waited for 30 days (AA+hAMSCs+ $30 ; n=5$ ) and (vi) the other MSCs group was waited 60 days (AA+hAMSCs $+60 ; n=6)$ and sacrificed. Furthermore, all cell treated rats received daily subcutaneous injections of cyclosporine A (1 mg/day, Cell Signaling, Danvers, USA), starting one day before engraftment and continuing for seven days after engraftment.

\section{Functional and histological damage assessment}

Functional damage was evaluated by serum creatinine and urea levels. Blood samples were collected prior to sacrifice. Serum creatinine was analyzed by creatinine assay kit (Invitrogen, Paisley, UK) according to manufacturer's protocol. BUN was measured by serum urea with urea assay kit according to protocol of manufacturer (Invitrogen, Paisley, UK). Tissue damage was assessed through morphological analysis using Masson's Trichrome and Sirius Red (Sigma-Aldrich, St Louis, USA) staining. Percentage of fibrosis was measured by Image J (Maryland, USA).

\section{Immunohistochemistry and TUNEL analysis}

The immunohistochemical procedure has been described elsewhere (30). Briefly, slides were incubated with primer antibodies that are mouse monoclonal PCNA (1:1000, Cell Signaling), rabbit monoclonal Ki67 (1:100 dilution, Abcam) and mouse monoclonal human anti-Mitochondrial Antibody (1:250 dilution, Abcam), IL-6 (1:100 dilution, Abcam) and Collagen type I (1:100 dilution, Novus), through overnight at $4^{\circ} \mathrm{C}$. Staining was completed by performing LSAB 2 System-HRP (Dako) and then AEC system was used for developing. Hematoxylin counterstaining was performed. Apoptosis was determined by terminal transferase-mediated deoxyuridine triphosphate nick end-labeling (TUNEL) assay (In situ cell detection kit-POD, Roche, Risch-Rotkreuz, Switzerland) in paraffin-embedded tissue sections according to protocol of the manufacturer.

\section{Western blotting}

Immunoblot analysis were performed as described previously (31). Briefly, Membranes were incubated with PCNA (1:2000 dilution, Cell Signaling, Danvers, USA), p57 (1:250 dilution, Santa Cruz, Dallas, USA), PARP-1 (1:500 dilution, Abcam, Cambridge, UK) and Beta Actin (1:5000 dilution, Abcam, Cambridge, UK) at $4^{\circ} \mathrm{C}$ through overnight. Then the membranes were incubated with horseradish peroxidase ppconjugated IgG (Bio-Rad Laboratories, Inc., Hercules, USA) for $2 \mathrm{~h}$ at room temperature. SuperSignal CL-HRP Substrate System (Thermo Fisher Scientific, Waltham, USA) was used for immunolabeling. Membranes were exposed to Hyperfilm (Amersham, Little Chalfont, UK) and analyzed by using Alpha Digi Doc 1000 gel documentation unit (Alpha Innotech Corporation, San Leandro, USA).

\section{Statistical analyses}

Data were expressed as mean \pm SEM. One way ANOVA test was used to compare means of multiple groups using GraphPad Prism (version 4.0; GraphPad Software, La Jolla, USA). The level of statistical significance was set $\mathrm{p}<0.05$.

\section{Results}

\section{Characterization of hAMSCs}

Human placenta amnion membrane-derived MSCs that showed fibroblast-like phenotype were isolated. At passage 3, hAMSCs were characterized with cell surface markers by flow cytometry analyses: CD90, CD105, CD73, CD44 positive and negative cocktail containing CD34, CD11b, CD19, CD45 and HLA-DR with isotype controls. The percentages of cell surface markers were 98.8\%, 93.5\%, 95.3\%, 88.6\% and 3.9\% respectively (Fig. 1A-J).

Phase contrast microscopic images of human amniotic membrane MSCs in the second passage are given in Fig. $2 \mathrm{~A}$ and $2 \mathrm{~B}$. hMSCs were spindle or triangular shaped and adhered to plastic.

\section{hAMSCs undergo adipogenic, chondrogenic and osteogenic differentiation}

hAMSCs could differentiate into adipocytes, chondrocytes and osteocytes. To show lipid droplets, cells were stained with Oil Red $\mathrm{O}$ in adipocyte differentiation (Fig. 2C). To determine deposition of calcium, cells were stained with Alizarin Red $\mathrm{S}$ in osteocyte differentiation (Fig. 2D). To determine chondrocytes, cells were stained with Alcian Blue (Fig. 2E) and Sirius Red (Fig. 2F). 

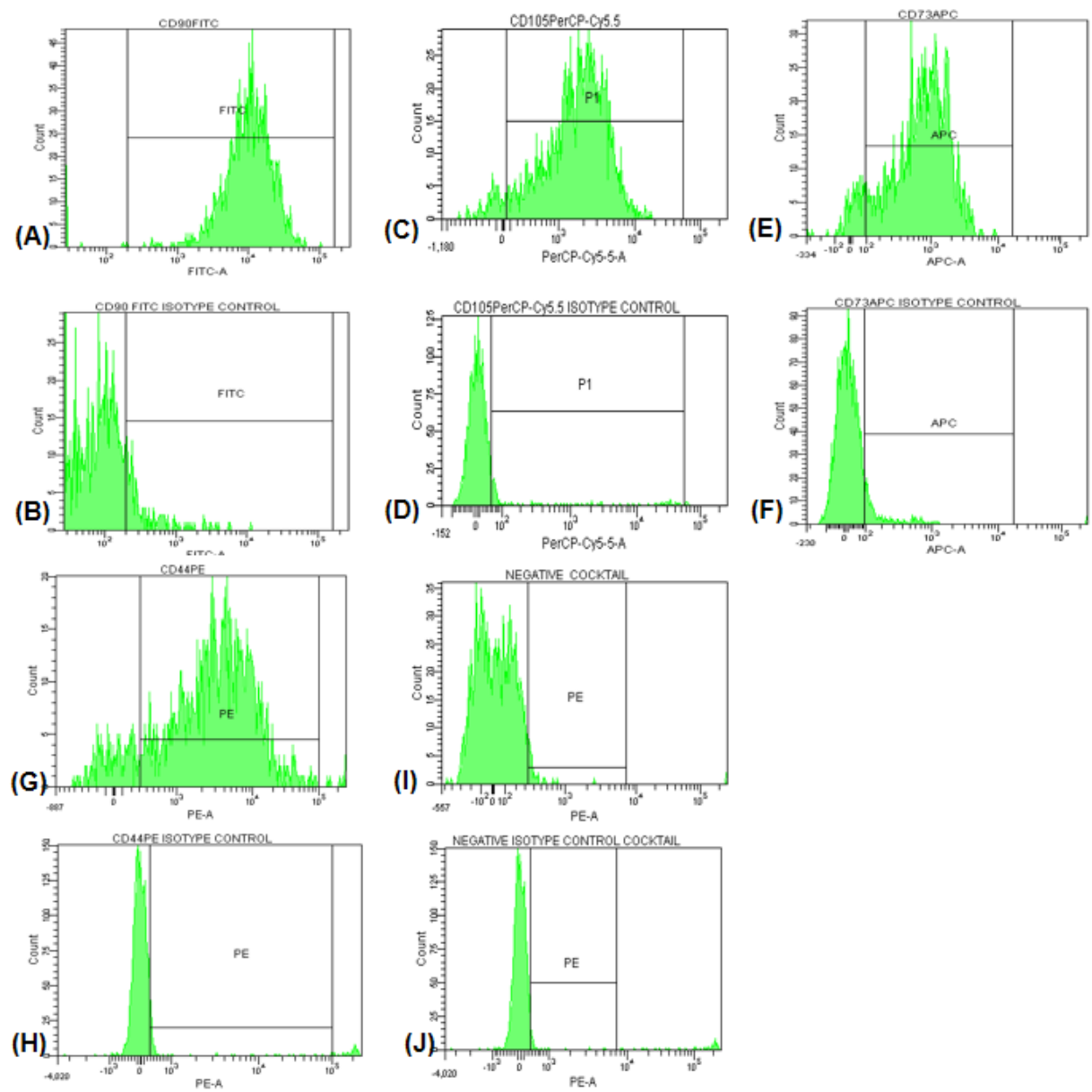

Fig. 1. hAMSC characterization. Flow cytometry analysis of hAMSCs for CD90 (A, B), CD105 (C, D), CD73 $(E, F), C D 44(G, H)$ and negative cocktail (I, J) with isotype controls.
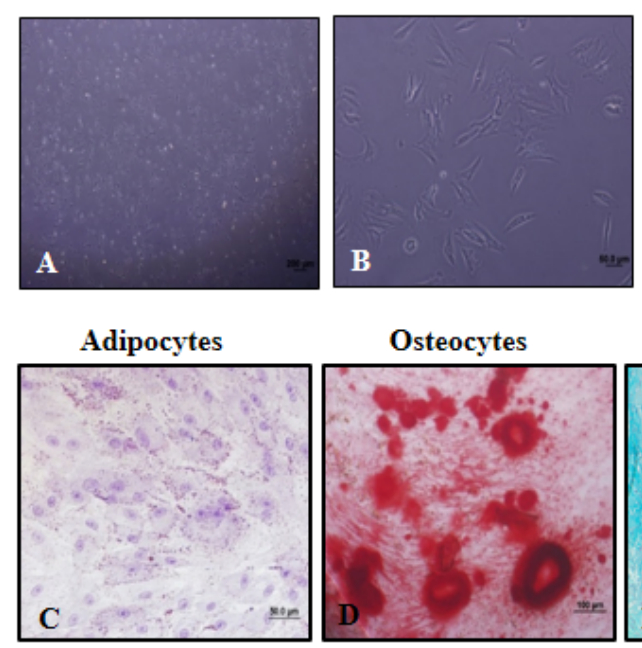

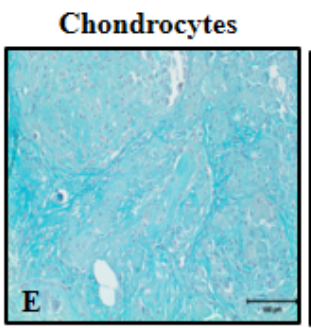

\section{Chondrocytes}

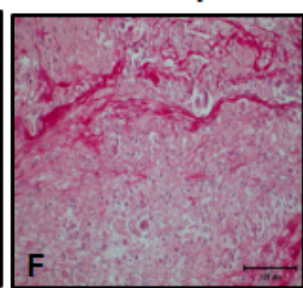

Fig. 2. Phase contrast microscopic images of human amniotic membrane derived mesenchymal stromal cells in 4X (A) and 40X magnifications (B). hAMSCs were differentiated into adipocytes (C., as shown by Oil Red O staining), osteocytes (D., as shown by Alizarin Red S staining) and chondrocytes (E and $\mathrm{F}$, as shown by Alcian Blue and Sirius Red staining).
While proteoglycans were stained with Alcian blue, collagens were stained with Sirius Red.

\section{Morphological studies}

To evaluate renal histology and determine renal fibrosis, paraffin-fixed specimens were sectioned at a thickness of $5 \mu \mathrm{m}$ and stained with Masson's Trichrome (Fig. 3A-D) 

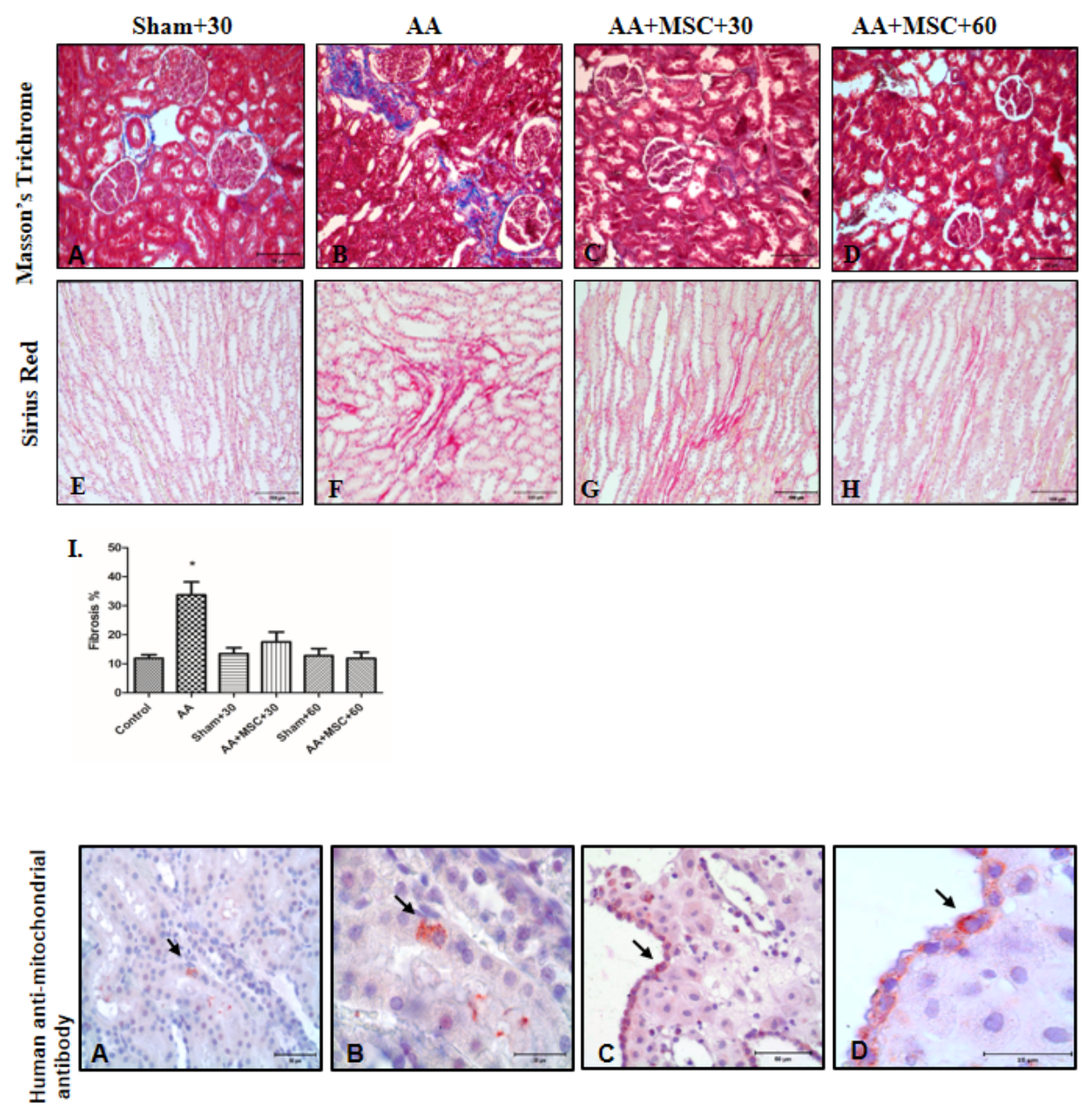

Fig. 4. At 30 day hAMSCs tracking in kidney tissue with immunolabeling of human anti-mitochondrial antibody (A, $\times 40, B, \times 100)$. Positive control is human decidua tissue $(C$, $\times 40, \mathrm{D}, \times 100$ ).

and Sirius Red (Fig. 3E-H). Increased extracellular matrix production was shown with Masson's Trichrome. Accumulation of collagen was shown with Sirius Red. There were no significant extracellular matrix and collagen in control and sham groups $(\mathrm{S}+30, \mathrm{~S}+60)$ (Fig. 3A, E). Morphological differences were not found between control and sham groups (control and $S+60$ results not shown). In $A A$ group, significant increase of extracellular matrix was observed near proximal and distal tubules compared to hAMSCs groups $(\mathrm{AA}+\mathrm{MSCs}+30$ and $\mathrm{AA}+\mathrm{MSCs}+60)$ (Fig. 3B). Also in AA group, accumulation of collagen was more than MSCs groups at the same area (Fig. 3F). Although rats were treated with hAMSCs, Masson's Trichrome and Sirius Red staining showed fibrosis reduction in both AA+hAMSCs groups (Fig. 3C and 3D) and (Fig. 3G and $3 \mathrm{H}$ ). The percentage of fibrosis measured with Image $\mathrm{J}$.

\section{MSC tracking}

To determine hAMSC localization in kidney tissues, im- munohistochemistry analysis was performed. We used human anti-mitochondrial antibody. hAMSC was observed in kidney tissues (Fig. 4A and 4B). Furthermore, human decidua tissue was used as a positive control for human anti-mitochondrial immunostaining (Fig. 4C and 4D).

\section{Proinflammatory cytokine IL-6 and Fibrosis marker collagen type I immunostaining}

Expressions of the proinflammatory cytokine IL-6 significantly increased in AA group especially in proximal and distal tubule cells. However, after hAMSCs injection expressions decreased both $\mathrm{AA}+\mathrm{hAMSC}+30$ and $\mathrm{AA}+$ hAMSC +60 groups significantly (Fig. 5A-D). Renal interstitial fibrosis was determined a significant increase in the collagen I protein in AA group compared to control group, sham groups, $\mathrm{AA}+\mathrm{hAMSC}+30$ and $\mathrm{AA}+\mathrm{hAMSC}+60$ groups. In hAMSCs groups expressions of collagen I decreased significantly (Fig. 5E-H). 
Proliferation (PCNA and Ki67 staining) and western blot analysis of PCNA expression

The proliferations markers PCNA and Ki67 were ex- pressed in sham group Kidney Tissue (Fig. 6A and 6E). The immunohistochemistry staining of PCNA and Ki67 in AA group kidneys were observed weak signal (Fig. 6B
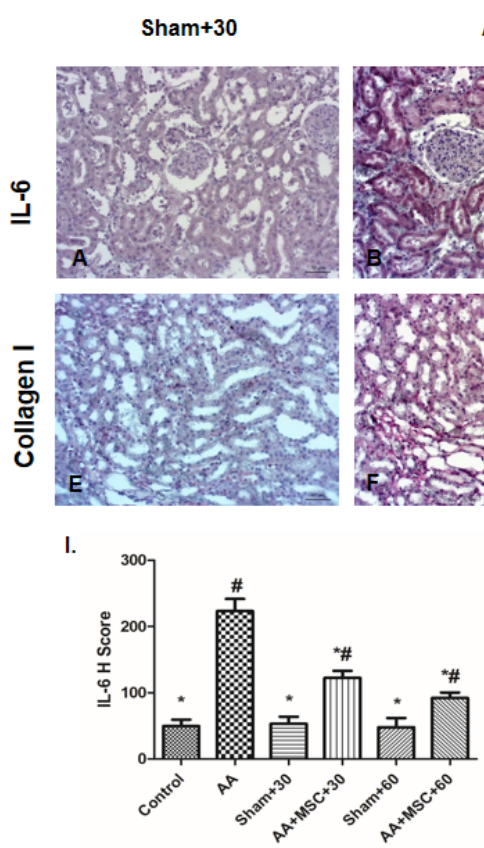

AA

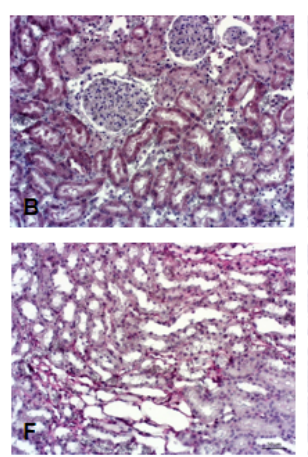

$A A+M S C+30$
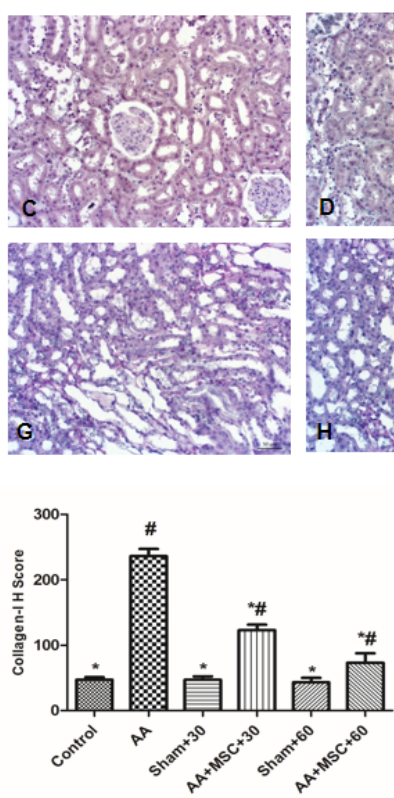

$\mathrm{AA}+\mathrm{MSC}+60$

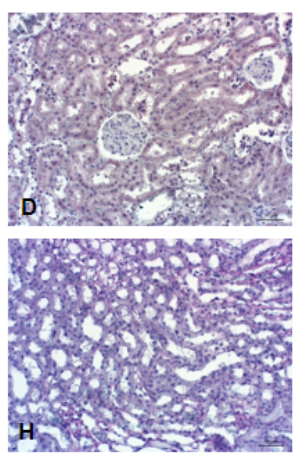

Fig. 5. Immunohistochemical staining of kidney tissue sections for the sham $+30, \quad A A, \quad A A+h A M S C+30$ and $\mathrm{AA}+\mathrm{hAMSC}+60$ groups using IL-6 (A-D), Collagen-I (E-H) I and J, $\mathrm{H}$ scores of IL-6 and Collagen-I. Values presented as mean $\pm \mathrm{SD}$. AA group compared with Sham, Control, $\mathrm{AA}+\mathrm{hAMSC}+30$, and AA+hAMSC +60 groups. Values statistically significant at: ${ }^{*} p<0.05$, Sham and Control groups compared with AA and hAMSC groups; ${ }^{*} p<0.05$.
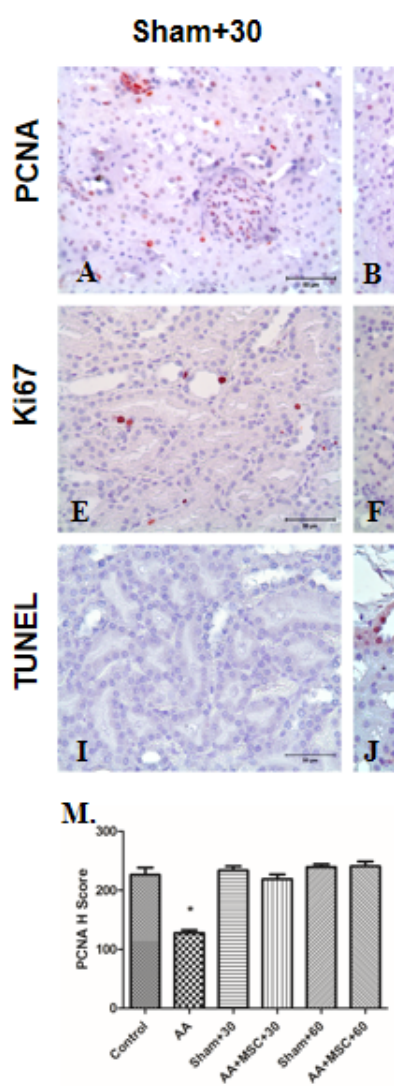

AA
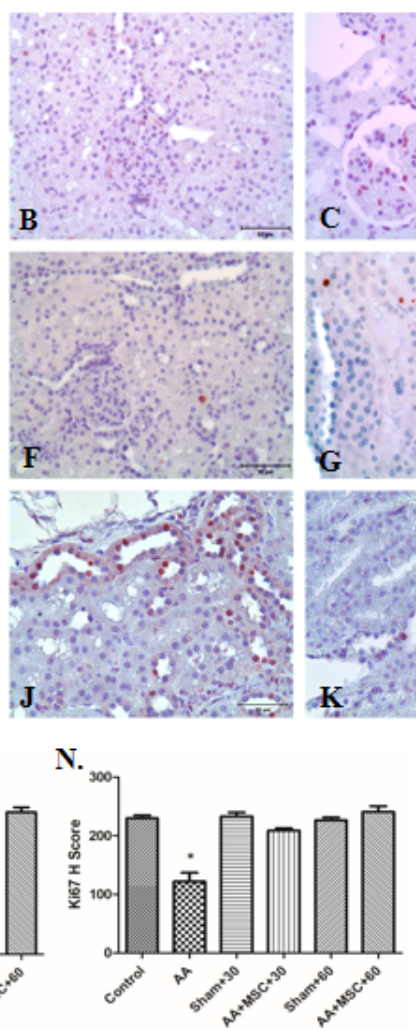

$A A+M S C+30$
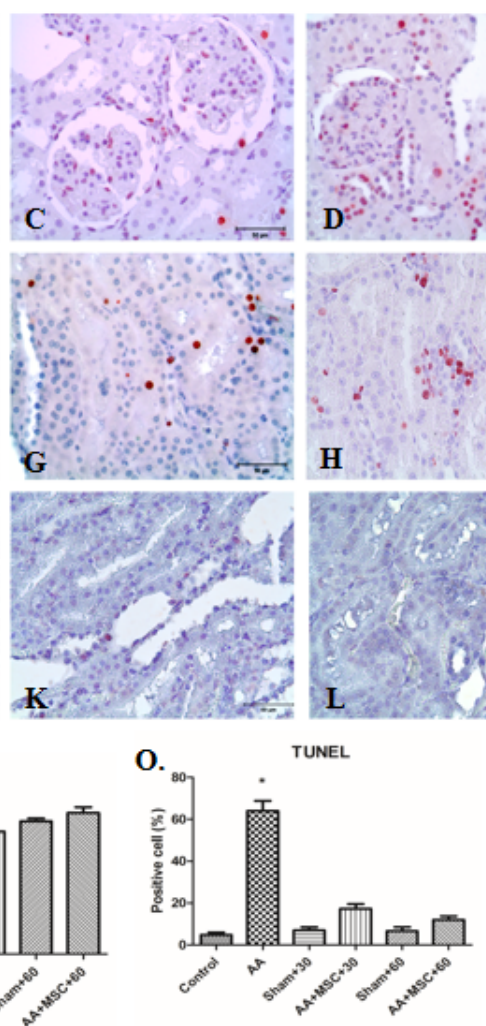

$\mathrm{AA}+\mathrm{MSC}+60$
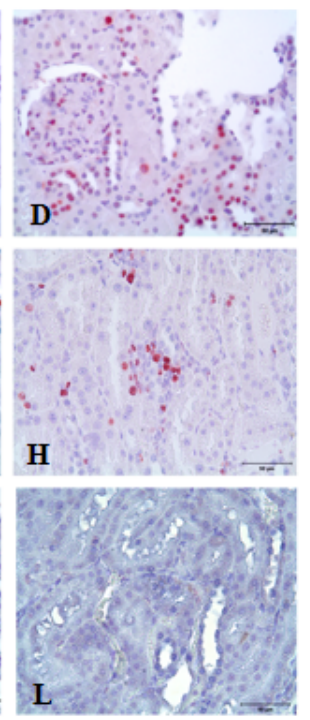

Fig. 6. PCNA, Ki67 and TUNEL immunostaining in kidneys tissue. For $\mathrm{PCNA}$, sham $+30(\mathrm{~A}), \mathrm{AA}(\mathrm{B}), \mathrm{AA}+$ hAMSC + 30 (C) and AA+hAMSC+ 60 (D) groups, for Ki67 sham +30 (E), AA (F), AA+hAMSC+30 (G) and $\mathrm{AA}+\mathrm{hAMSC}+60$ groups $(\mathrm{H})$ and for TUNEL immunostaining sham +30 (I), AA (J), AA+hAMSC $+30(\mathrm{~K})$ and $\mathrm{AA}+\mathrm{hAMSC}+60(\mathrm{~L})$ groups. $\mathrm{M}$ and $\mathrm{N}, \mathrm{H}$ scores of PCNA and Ki67. (O) Positive cells number for TUNEL. Values statistically significant at: ${ }^{*} p<0.05$. 


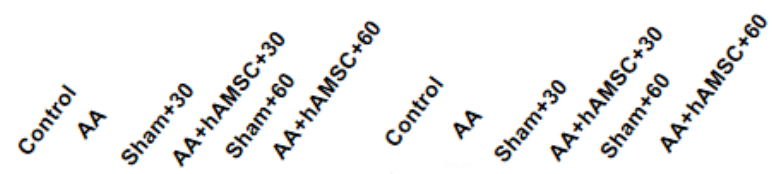

PCNA

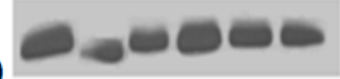

(36 kDa)

p57

(57 kDa)

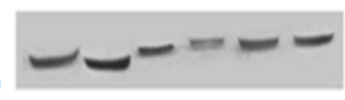

B-Actin

(42 kDa)
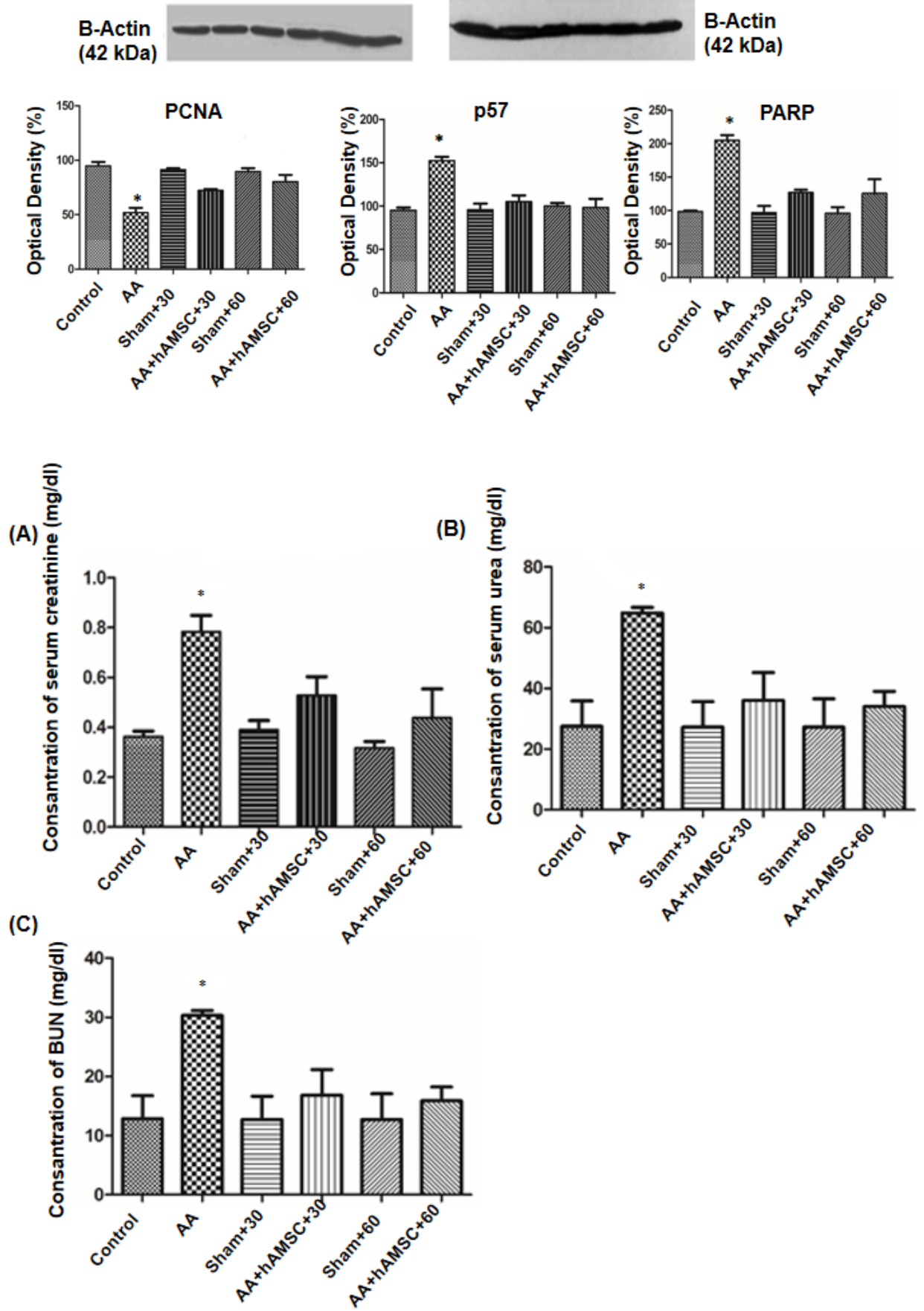

Cleaved-PARP
B-Actin

(42 kDa)

Total PARP

(113 kDa)

(25 kDa)

Fig. 7. Western blot results of PCNA, p57, total PARP and cleaved-PARP. AA administration caused increased PARP and p57 expressions but decreased PCNA compared with control, sham +30 and sham +60 . After hAMSC administration PARP and p57 expressions decreased and PCNA expression increased significantly. Protein levels between $\mathrm{AA}+\mathrm{hAMSC}+30$ and $\mathrm{AA}+\mathrm{hAMSC}$ +60 were not statistically significant. All results were normalized to beta actin. Graphics represent means of optical densitometry measurements. ${ }^{*} \mathrm{p}<0.005$.

Fig. 8. Functional damage assessment. Serum creatinine (A), serum urea (B) and BUN (C) levels were determined. AA administration caused increased serum creatinine, serum urea and BUN compared to control and sham groups significantly. After hAMSC administration, serum creatinine, serum urea and BUN levels decreased significantly. Graphics represent means of optical densitometry measurements. ${ }^{*} \mathrm{p}<0.005$ 
and $6 \mathrm{~F}$ ). However, after injection of hAMSCs, in both AA +hAMSCs groups cell proliferation was significantly increased. Increase of PCNA and Ki67 staining were observed especially in proximal and distal tubule cells. PCNA and Ki67 staining were not observed significant differences between $\mathrm{AA}+\mathrm{hAMSC}+30$ and $\mathrm{AA}+\mathrm{hAMSC}$ +60 groups (Fig. $6 \mathrm{C}$ and $6 \mathrm{D}$, and Fig. $6 \mathrm{G}$ and $6 \mathrm{H}$ ). Western blot analysis results showed that PCNA expression was decreased in the AA group compared with control, $S+30$ and $S+60$ groups. Furthermore, after hAMSCs injection, expression of PCNA was increased significantly in the AA+hAMSCs groups (Fig. 7).

\section{Apoptosis (TUNEL staining) and western blot analysis of PARP-1 expression}

In AA group, numbers of apoptotic cells were observed to increase compared with sham groups (Fig. $6 \mathrm{~K}$ and $6 \mathrm{~L}$ ). When rats treated with hAMSCs, apoptotic cells were reduced significantly in tubules (Fig. $6 \mathrm{M}$ and $6 \mathrm{~N}$ ). We determined expression of Parp-1 protein as an apoptosis marker. In western blot analysis, Parp-1 expression of AA group was compared with that of control and sham groups. In AA group, apoptosis level was higher than control and sham groups. However, after hAMSCs injection, Parp-1 expression level of both AA+hAMSCs groups was decreased significantly compared with AA group. Therefore, TUNEL results supported western blot analysis of Parp-1 expression (Fig. 7).

\section{Western blot analysis of $\mathrm{p} 57$ expression}

In AA group, p57 expression was increased compared with control and sham groups. However, p57 expression level was reduced compared to AA group after hAMSCs injection. Differences were not finding between both hAMSC groups and control and sham groups in expression of p57 significantly (Fig. 7).

\section{Functional renal damage studies}

Renal function was assessed by serum creatinine and BUN. Therefore, the development of CKD was evaluated in model of AAN. AA group rats showed significantly higher levels of serum creatinine and BUN than normal control and sham groups. When rats were treated with a single intravenous of $6 \times 10^{5}$ hAMSCs after AAN, serum creatinine and BUN levels were decreased significantly according to levels of AA group. Furthermore, creatinine and BUN levels of the both AA+hAMSCs groups were not significantly different from normal control and sham groups (Fig. 8).

\section{Discussion}

CKD increases day after day as a public health problem. Recently, cell therapies are applying for the repair of kidney injury. More studies, stem cell transplantation was carried out to damage kidney for provision of renal repair (32-36). Human amniotic membrane is thought to be a reservoir of mesenchymal stem cell. For these reason, hAMSCs has been the focus of interest as a source of MSCs in cell transplantation and regenerative medicine. In this study, we showed that a single administration of amniotic membrane derived MSCs prevents CKD after induction of AAN in rats.

Several studies showed that the administration of MSCs protects rats against CKD in different models. To ensure recovery after application of MSCs could be explained by several mechanisms. MSCs can differentiate into kidney cells. One of the mechanisms is paracrine effect. In model of chronic allograft nephropathy, MSCs migrated to the injured tissue and integrated to kidney. Briefly, MSCs has been determined to ameliorate the process of fibrosis when MSCs applied in the CKD model $(25,35,37,38)$.

In present study, CKD model was constituted after 6 weeks AA injection, rats were waited six weeks. Therefore, AA induced CKD model was occurred after total 12 weeks. We determined fibrosis with Masson's Trichrome and Sirius Red staining. In addition expressions of collagen-I was determined with immunohistochemistry staining. In AA group, fibrosis increased significantly compared with control and sham groups. Particularly, accumulation of collagen occurred in the vicinity glomeruli, proximal and distal tubules. Recent studies showed that the primarily target of AA is proximal tubules. According to Huang et al, AA applied kidney is showed to increase collagen in interstitial area (39). After hAMSC administration, accumulation of collagen decreased compared with AA group. Therefore, tubular damage was considered to ameliorate after hAMSCs injection.

In $\mathrm{CKD}$, damaged tubular cells, macrophages, accumulating fibroblasts and infiltrating lymphocytes produce cytokines and growth factors, causing the kidneys to become inflammatory. This inflammation leads to interstitial fibrosis (40). Therefore, the levels of expression of the proinflammatory cytokine IL-6 was determined by immunohistochemistry. In AA group, expressions of IL-6 significantly increased. However after hAMSCs injection reduced expressions of IL- 6 both AA + hAMSC +30 and AA + hAMSC +60 groups.

Renal functions are damaged rapidly in AAN and end-stage renal failure arises in a few months. Both in vi- 
tro and in vivo studies, specific AA-DNA adduction formation was demonstrated in renal epithelial cells after AA injection and this formation can prevent proximal tubular epithelial cells (PTEC) proliferation capacity. Besides, apoptosis was determined in CKD and this condition was suggested to be mechanism of tubular epithelial cell deletion. Progressing tubular atrophy correlate with unrecoverable regeneration and apoptosis of PTEC. Additionally, staining of Ki67 and PCNA inform about DNA damage. The reduction of PCNA expression in PTECs, AA-DNA addition formation is considered impairment of DNA repair and this situation induces defective cell proliferation and tubular atrophy (11). In present study, AA injected group was observed to decrease PCNA and Ki67 immunohistochemistry staining compared with control and sham groups. The reason for this is due to degradation of DNA repair mechanism, AA-DNA addition formation occurred. This condition indicated that reduction of proliferation in AA injected group. Furthermore, cell death was determined with TUNEL and western blot analysis of PARP-1 protein expression. In accordance with other studies $(36,41)$ both TUNEL and western blot analysis indicated that apoptosis increased in AA group compared to other groups. Li et al. reported that cell cycle arrest of PTECs was occurred after AA injection (42). We observed that expression of p57 increased in AA group compared with other groups. Therefore, unrecoverable PTECs can lead to apoptosis.

Sun et al. evaluated the use of human amniotic fluid stem cells (hAFSCs) in cell-based therapy (36). They investigated whether hAFSCs effect on interstitial fibrosis in unilateral urethral obstruction which is one of the $\mathrm{CKD}$ model. Therefore, proliferation and apoptosis mechanisms of tubular cells were investigated to evaluate therapeutic effect of hAFSCs injection. The mechanism that covers proliferation and apoptosis of tubular epithelial cell includes paracrine effect. Furthermore, proliferation of resident epithelial cells was suggested that a mechanism of basic-repair in ischemia induced tubular injury model (36).

Gatti et al investigated that MSCs derived microvesicles administration can ameliorate ischemia-reperfusion induced acute kidney disease (AKD) and CKD (41). After injection, microvesicles accumulated in glomeruli and damaged tubules temporarily and they induced proliferation of tubular cell. Furthermore, microvesicles reduced significantly tubular cell apoptosis. These biological effects are specific for MSC derived microvesicles because these effects were not seen in fibroblast derived microvesicles (41).
In this study, fibrosis can be considered to ameliorate due to increasing of renal tissue cell proliferation after hAMSCs administration. This study suggested that hAMSCs have an important role in tubular atrophy and hAMSCs can prevent damage formation in PTECs and other cells. This situation shows that hAMSCs have therapeutic features. In addition to, the increase of proliferation is considered to cause hAMSCs can replace with damaged cell and differentiate into adult tissue cells. Furthermore, hAMSCs have paracrine effects thus they can secrete various growth factors and cytokines.

We observed expression of apoptosis marker and cell cycle inhibitor decreased significantly after hAMSCs administration. Therefore, apoptosis can be prevented due to tubular cell regeneration.

Recent studies were reported that serum creatinine, BUN, urea levels decreased significantly after MSCs injection in various CKD models $(26,41,43)$. In present study, when serum creatinine, serum urea and BUN levels were analyzed, we observed to increase in AA group compared with control and sham groups. After hAMSCs administration, levels of serum creatinine, serum urea and BUN decreased significantly. In AA-induced CKD model after hAMSCs injection, reduction of serum creatinine, urea and BUN levels indicate that hAMSCs have renoprotective effects.

\section{Conclusion}

Consequently, we suggest that hAMSCs can play an active role to ameliorate renal damage and they can prevent the induction of apoptosis because of fibrosis. Therefore, hAMSCs have therapeutic effect in CKD.

\section{Acknowledgements}

This study was supported by Research Foundation of Akdeniz University, Turkey (project number: TYL-2014131).

\section{Potential Conflict of Interest}

The authors have no conflicting financial interest.

\section{References}

1. Little MH. Regrow or repair: potential regenerative therapies for the kidney. J Am Soc Nephrol 2006;17:2390-2401

2. Nangaku M. Mechanisms of tubulointerstitial injury in the kidney: final common pathways to end-stage renal failure. Intern Med 2004;43:9-17

3. Vanhaelen M, Vanhaelen-Fastre R, But P, Vanherweghem JL. Identification of aristolochic acid in Chinese herbs. 


\section{Lancet $1994 ; 343: 174$}

4. De Broe ME. Chinese herbs nephropathy and Balkan endemic nephropathy: toward a single entity, aristolochic acid nephropathy. Kidney Int 2012;81:513-515

5. Nortier JL, Deschodt-Lanckman MM, Simon S, Thielemans NO, de Prez EG, Depierreux MF, Tielemans CL, Richard C, Lauwerys RR, Bernard AM, Vanherweghem JL. Proximal tubular injury in Chinese herbs nephropathy: monitoring by neutral endopeptidase enzymuria. Kidney Int 1997;51:288-293

6. Vanherweghem JL, Depierreux M, Tielemans C, Abramowicz D, Dratwa M, Jadoul M, Richard C, Vandervelde D, Verbeelen D, Vanhaelen-Fastre R. Rapidly progressive interstitial renal fibrosis in young women: association with slimming regimen including Chinese herbs. Lancet 1993; 341:387-391

7. Schmeiser HH, Bieler CA, Wiessler $M$, van Ypersele de Strihou C, Cosyns JP. Detection of DNA adducts formed by aristolochic acid in renal tissue from patients with Chinese herbs nephropathy. Cancer Res 1996;56:2025-2028

8. Nortier JL, Martinez MC, Schmeiser HH, Arlt VM, Bieler CA, Petein M, Depierreux MF, De Pauw L, Abramowicz D, Vereerstraeten P, Vanherweghem JL. Urothelial carcinoma associated with the use of a Chinese herb (Aristolochia fangchi). N Engl J Med 2000;342:1686-1692

9. Lebeau C, Arlt VM, Schmeiser HH, Boom A, Verroust PJ, Devuyst O, Beauwens R. Aristolochic acid impedes endocytosis and induces DNA adducts in proximal tubule cells. Kidney Int 2001;60:1332-1342

10. Lebeau C, Debelle FD, Arlt VM, Pozdzik A, De Prez EG, Phillips DH, Deschodt-Lanckman MM, Vanherweghem JL, Nortier JL. Early proximal tubule injury in experimental aristolochic acid nephropathy: functional and histological studies. Nephrol Dial Transplant 2005;20:2321-2332

11. Pozdzik AA, Salmon IJ, Debelle FD, Decaestecker C, Van den Branden C, Verbeelen D, Deschodt-Lanckman MM, Vanherweghem JL, Nortier JL. Aristolochic acid induces proximal tubule apoptosis and epithelial to mesenchymal transformation. Kidney Int 2008;73:595-607

12. Soylemezoglu O, Wild G, Dalley AJ, MacNeil S, Milford-Ward A, Brown CB, el Nahas AM. Urinary and serum type III collagen: markers of renal fibrosis. Nephrol Dial Transplant 1997;12:1883-1889

13. Liu Y. Cellular and molecular mechanisms of renal fibrosis. Nat Rev Nephrol 2011;7:684-696

14. Sun D, Feng J, Dai C, Sun L, Jin T, Ma J, Wang L. Role of peritubular capillary loss and hypoxia in progressive tubulointerstitial fibrosis in a rat model of aristolochic acid nephropathy. Am J Nephrol 2006;26:363-371

15. Yang L, Li X, Wang H. Possible mechanisms explaining the tendency towards interstitial fibrosis in aristolochic acid-induced acute tubular necrosis. Nephrol Dial Transplant 2007;22:445-456

16. Barry FP, Murphy JM. Mesenchymal stem cells: clinical applications and biological characterization. Int J Biochem Cell Biol 2004;36:568-584
17. Lange C, Tögel F, Ittrich H, Clayton F, Nolte-Ernsting C, Zander AR, Westenfelder C. Administered mesenchymal stem cells enhance recovery from ischemia/reperfusion-induced acute renal failure in rats. Kidney Int 2005;68:16131617

18. Kunter U, Rong S, Djuric Z, Boor P, Müller-Newen G, Yu D, Floege J. Transplanted mesenchymal stem cells accelerate glomerular healing in experimental glomerulonephritis. J Am Soc Nephrol 2006;17:2202-2212

19. Bi $B$, Schmitt $R$, Israilova $M$, Nishio $H$, Cantley LG. Stromal cells protect against acute tubular injury via an endocrine effect. J Am Soc Nephrol 2007;18:2486-2496

20. Hopkins C, Li J, Rae F, Little MH. Stem cell options for kidney disease. J Pathol 2009;217:265-281

21. Dominici M, Le Blanc K, Mueller I, Slaper-Cortenbach I, Marini F, Krause D, Deans R, Keating A, Prockop Dj, Horwitz E. Minimal criteria for defining multipotent mesenchymal stromal cells. The International Society for Cellular Therapy position statement. Cytotherapy 2006;8: 315-317

22. Jin CZ, Park SR, Choi BH, Lee KY, Kang CK, Min BH. Human amniotic membrane as a delivery matrix for articular cartilage repair. Tissue Eng 2007;13:693-702

23. Díaz-Prado S, Muiños-López E, Hermida-Gómez T, Rendal-Vázquez ME, Fuentes-Boquete I, de Toro FJ, Blanco FJ. Multilineage differentiation potential of cells isolated from the human amniotic membrane. J Cell Biochem 2010; 111:846-857

24. Parolini O, Alviano F, Bagnara GP, Bilic G, Bühring HJ, Evangelista M, Hennerbichler S, Liu B, Magatti M, Mao N, Miki T, Marongiu F, Nakajima $H$, Nikaido $T$, Portmann-Lanz CB, Sankar V, Soncini M, Stadler G, Surbek D, Takahashi TA, Redl H, Sakuragawa N, Wolbank S, Zeisberger S, Zisch A, Strom SC. Concise review: isolation and characterization of cells from human term placenta: outcome of the first international Workshop on Placenta Derived Stem Cells. Stem Cells 2008;26:300-311

25. Choi S, Park M, Kim J, Hwang S, Park S, Lee Y. The role of mesenchymal stem cells in the functional improvement of chronic renal failure. Stem Cells Dev 2009;18:521-529

26. Semedo P, Correa-Costa M, Antonio Cenedeze M, Maria Avancini Costa Malheiros D, Antonia dos Reis M, Shimizu $\mathrm{MH}$, Seguro AC, Pacheco-Silva A, Saraiva Camara NO. Mesenchymal stem cells attenuate renal fibrosis through immune modulation and remodeling properties in a rat remnant kidney model. Stem Cells 2009;27:3063-3073

27. Villanueva S, Ewertz E, Carrión F, Tapia A, Vergara C, Céspedes C, Sáez PJ, Luz P, Irarrázabal C, Carreño JE, Figueroa F, Vio CP. Mesenchymal stem cell injection ameliorates chronic renal failure in a rat model. Clin Sci (Lond) 2011;121:489-499

28. Klinkhammer BM, Kramann R, Mallau M, Makowska A, van Roeyen CR, Rong S, Buecher EB, Boor P, Kovacova K, Zok S, Denecke B, Stuettgen E, Otten S, Floege J, Kunter U. Mesenchymal stem cells from rats with chronic kidney disease exhibit premature senescence and loss of re- 
generative potential. PLoS One 2014;9:e92115

29. Soncini M, Vertua E, Gibelli L, Zorzi F, Denegri M, Albertini A, Wengler GS, Parolini O. Isolation and characterization of mesenchymal cells from human fetal membranes. J Tissue Eng Regen Med 2007;1:296-305

30. Korgun ET, Celik-Ozenci C, Seval Y, Desoye G, Demir R. Do glucose transporters have other roles in addition to placental glucose transport during early pregnancy? Histochem Cell Biol 2005;123:621-629

31. Ozmen A, Unek G, Kipmen-Korgun D, Korgun ET. The expression of Akt and ERKl/2 proteins decreased in dexamethasone-induced intrauterine growth restricted rat placental development. J Mol Histol 2011;42:237-249

32. Lin F, Cordes K, Li L, Hood L, Couser WG, Shankland SJ, Igarashi P. Hematopoietic stem cells contribute to the regeneration of renal tubules after renal ischemia-reperfusion injury in mice. J Am Soc Nephrol 2003;14:11881199

33. Broekema M, Harmsen MC, Koerts JA, Petersen AH, van Luyn MJ, Navis G, Popa ER. Determinants of tubular bone marrow-derived cell engraftment after renal ischemia/reperfusion in rats. Kidney Int 2005;68:2572-2581

34. Fang TC, Otto WR, Rao J, Jeffery R, Hunt T, Alison MR, Cook HT, Wright NA, Poulsom R. Haematopoietic lineage-committed bone marrow cells, but not cloned cultured mesenchymal stem cells, contribute to regeneration of renal tubular epithelium after $\mathrm{HgCl} 2$-induced acute tubular injury. Cell Prolif 2008;41:575-591

35. Humphreys BD, Bonventre JV. Mesenchymal stem cells in acute kidney injury. Annu Rev Med 2008;59:311-325

36. Sun D, Bu L, Liu C, Yin Z, Zhou X, Li X, Xiao A. Thera- peutic effects of human amniotic fluid-derived stem cells on renal interstitial fibrosis in a murine model of unilateral ureteral obstruction. PLoS One 2013;8:e65042

37. Cosyns JP, Dehoux JP, Guiot Y, Goebbels RM, Robert A, Bernard AM, van Ypersele de Strihou C. Chronic aristolochic acid toxicity in rabbits: a model of Chinese herbs nephropathy? Kidney Int 2001;59:2164-2173

38. Inumaru J, Nagano O, Takahashi E, Ishimoto T, Nakamura S, Suzuki Y, Niwa S, Umezawa K, Tanihara H, Saya H. Molecular mechanisms regulating dissociation of cell-cell junction of epithelial cells by oxidative stress. Genes Cells 2009;14:703-716

39. Huang L, Scarpellini A, Funck M, Verderio EA, Johnson TS. Development of a chronic kidney disease model in C57BL/6 mice with relevance to human pathology. Nephron Extra 2013;3:12-29

40. Grande MT, Pérez-Barriocanal F, López-Novoa JM. Role of inflammation in túbulo-interstitial damage associated to obstructive nephropathy. J Inflamm (Lond) 2010;7:19

41. Gatti S, Bruno S, Deregibus MC, Sordi A, Cantaluppi V, Tetta C, Camussi G. Microvesicles derived from human adult mesenchymal stem cells protect against ischaemia-reperfusion-induced acute and chronic kidney injury. Nephrol Dial Transplant 2011;26:1474-1483

42. Li Y, Liu Z, Guo X, Shu J, Chen Z, Li L. Aristolochic acid I-induced DNA damage and cell cycle arrest in renal tubular epithelial cells in vitro. Arch Toxicol 2006;80:524-532

43. Cavaglieri RC, Martini D, Sogayar MC, Noronha IL. Mesenchymal stem cells delivered at the subcapsule of the kidney ameliorate renal disease in the rat remnant kidney model. Transplant Proc 2009;41:947-951 